\title{
Lipid Involvement in Viral Infections: Present and Future Perspectives for the Design of Antiviral Strategies
}

\author{
Miguel A. Martín-Acebes, Ángela Vázquez-Calvo, \\ Flavia Caridi, Juan-Carlos Saiz and Francisco Sobrino
}

Additional information is available at the end of the chapter

http://dx.doi.org/10.5772/51068

\section{Introduction}

Viruses constitute important pathogens that can infect animals, including humans and plants. Despite their great diversity, viruses share as a common feature the dependence on host cell factors to complete their replicative cycle. Among the cellular factors required by viruses, lipids play an important role on viral infections [1-4]. The involvement of lipids in the infectious cycle is shared by enveloped viruses (those viruses whose infectious particle is wrapped by one or more lipid membranes) and non-enveloped viruses [1-4]. Apart from taking advantage on cellular lipids that are usually located inside cells, viruses induce global metabolic changes on infected cells, leading to the rearrangement of the lipid metabolism to facilitate viral multiplication [1,5-11]. In some cases, these alterations produce the reorganization of intracellular membranes of the host cell, building the adequate microenvironment for viral replication [12,13]. All these findings highlight the intimate connections between viruses and lipid metabolism. Along this line, modulation of cellular lipid metabolism to interfere with virus multiplication is currently raising as a feasible antiviral approach $[6,14]$.

\section{A lipid perspective of the virus life cycle}

Inherent to their condition of obligate intracellular parasites, viruses have to invade a cell to complete their replicative cycle. During this step, viruses express their own proteins and also co-opt host cell factors for multiplication, including lipids [15]. A schematic view of a virus replication cycle is shown in Figure 1. Initial steps of viral infection include the attachment of the virus particle to a specific receptor located on the cell surface, in some 
cases a specific lipid (section 2.1.1). The viral genome has to entry into the host cell to reach the replication sites. Different lipids, located either on plasma and/or endosomal membranes, can contribute to these processes by enabling receptor clustering, virus internalization, or membrane fusion (sections 2.1.2 and 2.1.3). Replication of viral genome can take place associated to cellular membranes or other lipid structures, like lipid droplets, forming structures termed replication complexes (section 2.2). Newly synthesized viral genomes are enclosed inside de novo synthesized viral particles, a process in which several lipids can play, again, an important role (section 2.3), especially in the case of viruses containing a lipid envelope as an integral component of their infectious particle. Then, viral particles maturate to render infectious particles that are released from host cell to initiate a new infection cycle.

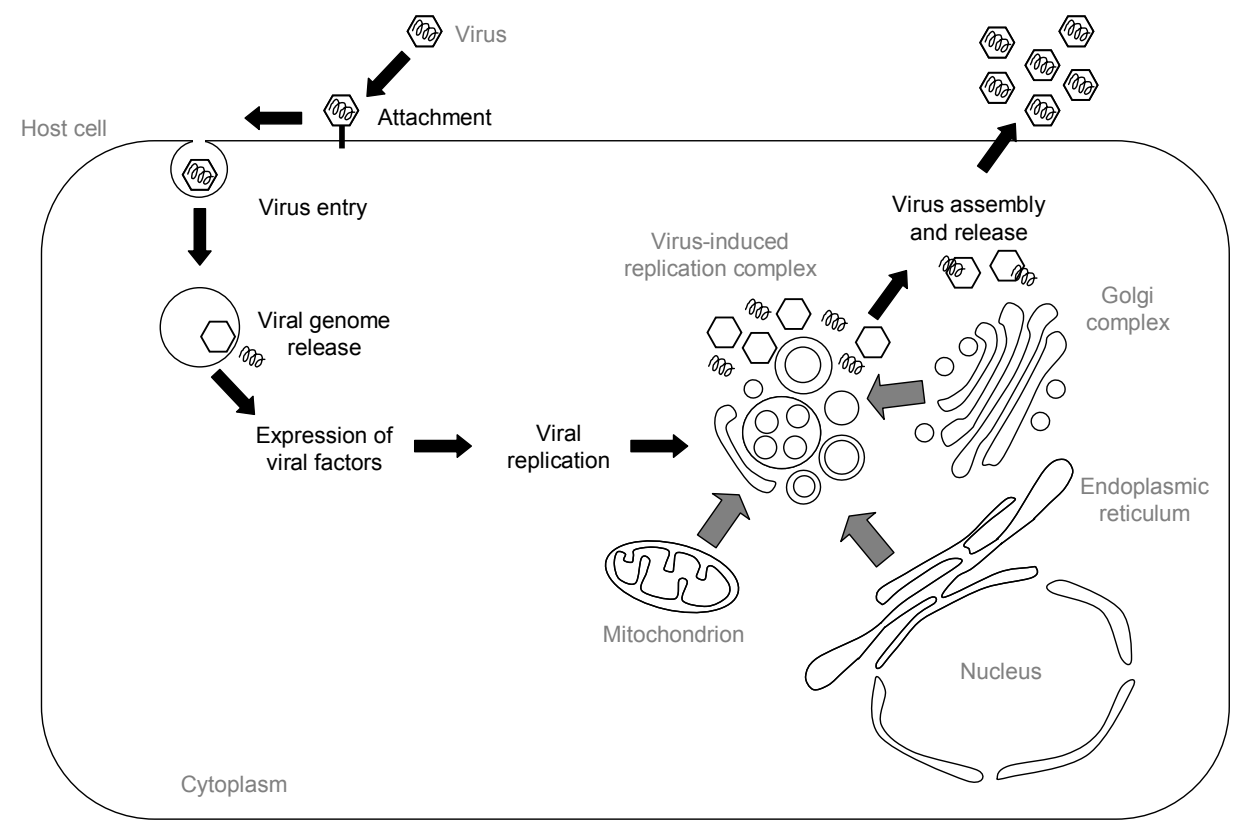

Figure 1. Schematic view of a virus replication cycle. For a detailed description of the different roles of lipids during virus infection see the text.

\subsection{Lipids and viral entry}

The viral entry into a host cell to start their replicative cycle involves the attachment of the virus particle to a specific receptor(s) located on the cell surface, prior to the introduction of the viral genome within the host cell. The latter can take place by internalization of the whole viral particle, constituting a sort of minute Trojan horse [16], or by direct penetration of viral genome from plasma membrane. During these processes, a variety of specific lipids play multiple roles, which may vary between viruses (Table 1 ). 


\begin{tabular}{llll}
\hline Virus & Lipid & Function & Refs. \\
\hline VSV & phosphatidylserine & Cellular receptor & {$[17]$} \\
& LBPA & Cofactor for membrane fusion & {$[18,19]$} \\
SV40 & GM1 & Cellular receptor & {$[20]$} \\
& cholesterol & Lipid raft-caveola mediated endocytosis & {$[21]$} \\
DENV & LBPA & Cofactor for membrane fusion & {$[22]$} \\
VACV & phosphatidylserine & Induction of viral internalization & {$[23]$} \\
\hline
\end{tabular}

Abbreviations used in this Table: DENV, dengue virus; LBPA, lysobisphosphatidic acid; SV40, simian virus 40; VACV, vaccinia virus; VSV, vesicular stomatitis virus.

Table 1. Examples of lipids required for viral entry

\subsubsection{Lipids and viral attachment}

The first event of virus infection comprises the recognition of the target cell, which generally occurs through the interaction between the virus and a specific receptor on the cell surface. Receptors exploited by viruses include different macromolecules like proteins, carbohydrates and lipids. An increasing number of viruses is known to attach to lipidcontaining molecules. For instance, members of the Polyomaviridae family use gangliosides, being the binding highly specific [24]. The simian virus 40 (SV40) employs exclusively the ganglioside GM1, whereas the mouse polyomavirus can use GD1a and GT1b, and BK virus can utilize GD1b and GT1b [25-28]. Other important human pathogens, such as influenza virus (Orthomyxoviridae) and Human immunodeficiency virus, HIV (Retroviridae), can also bind to different gangliosides [29,30].

Another example of a virus whose receptor is supposed to be a lipid is the rhabdovirus vesicular stomatitis virus (VSV), which seems to gain cell entry through interaction with negatively charged phospholipids, like phosphatidylserine [17]. VSV particles interact very strongly with membranes containing phosphatidylserine through viral glycoprotein G [31], and although it is not actually clear whether phosphatidylserine is the viral receptor [32], a direct interaction between the $G$ protein and this lipid could take place in the membrane [31].

On the other hand, some members of the Flaviviridae family -hepatitis $\mathrm{C}$ virus (HCV), GB virus $\mathrm{C}$ /hepatitis $\mathrm{G}$ virus and bovine viral diarrhea virus (BVDV)-, use the low-density lipoprotein receptor (LDL-R) [33], which is a cholesterol receptor. An interesting case is hepatitis $\mathrm{C}$ virus $(\mathrm{HCV})$ that requires the interaction with the low-density lipoprotein receptor (LDL-R) and with glycosaminoglycans to entry into the cell [8]. The component of the virion that interacts with LDL-R likely is a cell-derived lipoprotein, i. e. a virallipoprotein (section 2.3.1).

\subsubsection{Lipids and viral internalization}

Cells use a broad spectrum of mechanisms to internalize substances from their environment. Endocytosis is a general term for the internalization of particles, solutes, fluids, and membrane components by invagination of the plasma membrane and internalization of the 
resulting membrane vesicles [24,34-36]. The plasma membrane does not present a continuous or homogeneous composition. It contains lipid microdomains termed lipid rafts [37], characterized by their high content of cholesterol, glycosphinglolipids, glycophosphatidylinositol (GPI), anchored proteins like the GPI-anchored, myristoylated and palmytoylated proteins, as well as transmembrane proteins [38]. Lipid rafts have been associated with various endocytic mechanisms to internalize these membrane regions [3942], being the formation of cave-shaped invaginations, termed caveolae, the predominant mechanism [24,34]. Lipid rafts have been related to the entry of a number of viruses, for example the coronavirus severe acute respiratory syndrome (SARS), murine leukemia virus, herpes simplex virus, Japanese encephalitis virus, SV40, and echovirus 1 [34,43-48]. In addition, some viruses require cholesterol-enriched microdomains in the viral membrane for efficient virus entry, for example influenza virus A, human herpes virus 6, and Canine distemper virus [49-51]. On the other hand, some viruses that enter into the cells using mechanisms independent of lipid rafts require cholesterol for an efficient internalization. This is the case of foot-and-mouth disease virus (FMDV) and human rhinovirus type 2, whose entry into cells, by clathrin-mediated endocytosis, requires the presence of plasma membrane cholesterol [52,53]. In other viruses such as HIV-1, a requirement of cholesterol for viral entry has been documented [47] and related to the clustering of viral receptors, thus enabling viral internalization [54]. This role of cholesterol and lipid-rafts has also been documented for coxsackievirus B3 (CVB3) infection [55].

The plasma membrane also exhibits clusters of other lipids like phosphatidylinositol 4,5bisphosphate $\left(\mathrm{PI}(4,5) \mathrm{P}_{2}\right)$ [56], which is a minor lipid of the inner leaflet of the plasma membrane with an important role in the clathrin-mediated endocytosis [57-60]. Even when the number of viruses that use clathrin-mediated endocytosis to entry into the cells is wide [61], the importance of this lipid in viral entry has not been analyzed in depth yet. However, it has been reported that $\mathrm{PI}(4,5) \mathrm{P}_{2}$ production by a specific lipid kinase is crucial for HIV-1 entry in permissive lymphocytes [62]. Likewise, foot-and-mouth disease virus (FMDV) and VSV require the presence of this phospholipid in the plasma membrane for internalization (Vázquez-Calvo et al., submitted).

As commented before, specific lipids located in the viral particles can also play a role on viral entry of enveloped viruses [8], including 'those located in' lipid rafts [49-51]. Vaccinia virus provides another example of the relationships between lipids located on the viral particle and viral entry. In this case, the presence of exposed phosphatidylserine in the viral envelope is critical to induce blebs on cellular membrane that promote virus internalization [23].

\subsubsection{Lipids and viral genome delivery}

Viruses have to release their genome from the particle to enable proper expression of viral proteins and genome replication within host cell. In the case of enveloped viruses, fusion between viral envelope and cellular membranes is a generalized strategy to facilitate these events. This process is assisted by viral proteins termed fusion proteins, and results in lipid mixing between the viral envelope and the target cellular membrane 
[63-66]. Viral fusion occurs either with the plasma membrane for $\mathrm{pH}$-independent viruses, or, in the case of viruses entering through receptor-mediated endocytosis, with membranes of endocytic organelles in which particles are internalized. There is evidence showing that both groups of viruses use fusion proteins that, via hydrophobic segments, interact with membrane lipids, leading to conformational changes that make them able for fusion [63-66]. Compelling evidence indicates that specific lipids can influence the compartment of virus uncoating and viral genome delivery into the cytosol $[22,67,68]$. A number of enveloped viruses take advantage of the low $\mathrm{pH}$ inside endosomes to promote endosome fusion, permitting viral genome release [69]. Thus, utilization of specific lipids allows the virus to ensure membrane fusion at the proper cellular compartment. For instance, DENV takes advantage of the anionic late endosome-specific lipid bis(monoacylglycero)phosphate (BMP), also named lysobisphosphatidic acid (LBPA), to promote virus fusion with the late endosomal membrane [22]. A relevant role of LBPA in promoting membrane fusion and lipid mixing has also been shown in VSV infection [70]. Initially, VSV envelope fuses with intraluminal vesicles inside multivesicular bodies, which later fuse with external membrane of the multivesicular body, allowing the release of viral nucleocapsid to the cytosol $[18,19]$. However, fusion of other viruses, such as influenza virus, does not rely on these lipids [70]. Cholesterol, a major and vital constituent of eukaryotic cellular membranes, has been implicated in promoting lipid transfer and fusion pore expansion in the virus-cell membrane fusion mediated by the haemagglutinin of influenza virus [68]. The presence of cholesterol on the target membrane also promotes West Nile virus (WNV) membrane fusion activity [71], and both cholesterol and sphingolipids, but not lipid-rafts, are required for alphavirus fusion [67].

Regarding the entry of non-enveloped viruses, it is generally believed that the mechanism(s) involved does not include membrane fusion activity. Nevertheless, recent data obtained from biochemical and structural studies indicate that the overall mechanisms of entry of certain non-enveloped viruses are similar to those of enveloped ones, and that capsid proteins can function in these activities in a manner similar to that of the membrane viral proteins [72]. For instance, the outer capsid protein VP5 of the non-enveloped rotaviruses and orbiviruses, shares secondary structural features with fusion proteins of enveloped viruses [73], like the capacity to associate with lipid rafts in cellular membranes [72]. These findings indicate that VP5 may be responsible for membrane penetration [74]. Post-translational modifications of viral proteins, i.e. myristoylation of capsid protein VP4 in poliovirus (PV) and VP2 of polyomavirus, have been related to the ability of these proteins to induce pores on cellular membranes for genome release $[75,76]$.

\subsection{Lipids and viral multiplication}

Following entry into the host cell, viruses have to produce accurate self-copies to generate new infectious viral particles. To this end, viruses use to recruit cellular factors, including lipids and enzymes involved in their metabolism. 


\subsubsection{Cellular membranes and viral replication complex assembly}

Viruses co-opt host cell factors to develop the most adequate environment for their replication, a feature that is especially highlighted by the viral replication complex found assembled inside cells infected with positive strand RNA viruses [2,15,77]. Viruses belonging to this group share as a common feature a viral genome consisting of one or more RNA molecules of positive polarity that mimic the characteristics of cellular messenger RNA (mRNA) to be translated into viral proteins. Positive strand RNA viruses comprise several viral families that include important animal (including human) and plant pathogens such as Picornaviridae (i.e. PV, FMDV), Flaviviridae (i.e. DENV, WNV, HCV), Caliciviridae (i.e. Nowalk virus), Coronaviridae (i.e. SARS coronavirus), or Togaviridae (i.e. rubella virus). Replication of positive-strand RNA viruses is tightly associated to intracellular lipid membranes derived from different organelles: endoplasmic reticulum, Golgi complex, mitochondria, chloroplasts, peroxisomes, vacuoles, endosomes, or lysosomes [2]. Besides membranes derived from cellular organelles, these viruses can also usurp cytoplasmic lipid droplets for their replication [78,79]. In this way, viral replication results in the induction of marked alterations of the intracellular architecture mainly characterized by the remodelling of cellular membranes. These alterations include intracellular membrane proliferation and changes on shape and size of membranous structures. Consequently, viral replication originates a variety of structures that may rely on different mechanisms for their generation [12,15]. Examples of these structures (Figure 2) include the formation of convoluted membranes and vesicle packets as a result of flavivirus replication [80-82], the development of heterogeneous vesicular structures that conform the membranous web found in HCV-infected cells [83], or the proliferation of vesicular structures (including double membrane vesicles) in cells infected by enteroviruses (a genus within the Picornaviridae family) like PV $[84,85]$.

Morphological changes on membrane shape induced by viral infections are accompanied by an enrichment in the viral and cellular components, including specific proteins and lipids [13,12]. Despite the diversity of the membrane alterations induced, these changes provide the physical scaffold for viral replication, thus offering the most suitable platform for viral replication complex assembly, and hence increasing the local concentration of specific cellular and viral factors necessary for replication [1,12]. In addition, membrane remodelling can also improve viral multiplication by hiding viral components from the innate immune system $[1,12,86]$. In flaviviruses (DENV and WNV) the evasion of interferon response has been shown to depend on the expression of hydrophobic viral proteins involved in membrane rearrangements [87-89]; in particular, the cholesterol content of these membranes is important to down regulate the interferon-stimulated antiviral signalling response to infection [90]. Related to this, antiviral interferon response also involves down regulation of sterol biosynthesis [91]. Likewise, lipid droplets, which can constitute platforms for viral replication, also play important roles on the coordination of immune responses [92].

All these changes in the membrane morphology and composition result in the formation of customized cellular microenvironments that support viral replication and can be actually considered novel virus-induced organelles [93-95]. Regarding the lipid composition of these structures, great progresses have been recently made (see below) that have uncovered the 

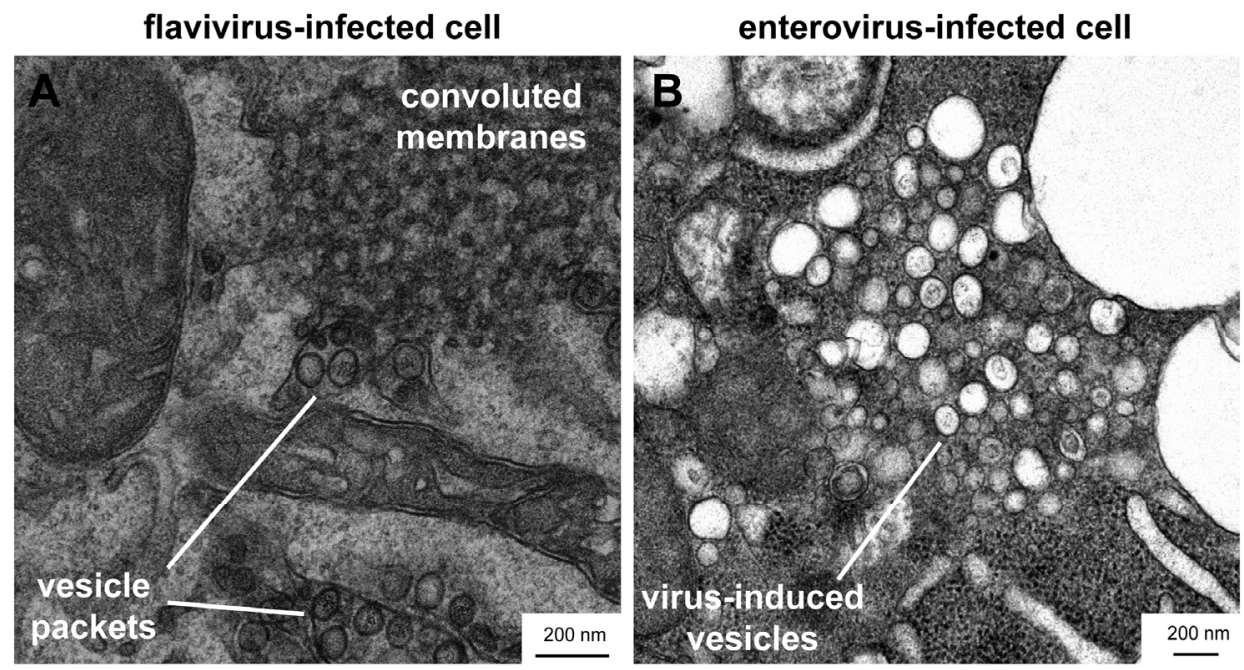

Figure 2. Distinct alterations on intracellular membrane architecture induced by the infection of positive strand RNA viruses. A) Induction of convoluted membranes and vesicle packets in flavivirus infected cells. Image corresponds to Vero cells infected with WNV, fixed and processed for transmission electron microscopy at $24 \mathrm{~h}$ post-infection. B) Proliferation of vesicular structures in enterovirusinfected cells. Porcine cells (IBRS-2) were infected with the enterovirus swine vesicular disease virus (SVDV), fixed, and processed for transmission electron microscopy at $7 \mathrm{~h}$ post-infection. For technical details related to virus infection and sample preparation see references $[81,84]$.

dependence on different cellular lipids for replication complex organization, although their roles and importance vary between viruses.

\subsubsection{Cellular lipids involved in viral replication complex assembly}

To render the specific lipid microenvironment adequate for multiplication, viruses co-opt cellular machinery for their replication, including host factors involved in different aspects of lipid metabolism, i.e. sterol biosynthesis, fatty acid metabolism and synthesis of specific phosphoinositides [15]. For instance, a marked alteration of cellular metabolism and an increase in fatty acid biosynthetic pathway have been described upon human cytomegalovirus (HCMV), DENV or HCV infection $[1,5,6,11]$. The association of viral multiplication with modulation of host cell factors involved in lipid metabolism is not an exclusive feature of animal viruses, thus, replication and recombination of the plant pathogens tombusviruses has been revealed to rely on host genes involved in lipid metabolism [96-99]. Representative examples of cellular factors related to lipid metabolism and associated to viral replication are summarized in Table 2.

Several studies have highlighted the role of the cholesterol and the cholesterol biosynthetic pathway in the replication of viruses, including important human pathogens belonging to the Flaviviridae family -WNV [90], DENV [110], and HCV [8,111-113]- and to the Caliciviridae -Nowalk virus [114]-families. In addition, the cholesterol biosynthetic pathway has also been 


\begin{tabular}{llll}
\hline Virus & Host factor & Function & Refs. \\
\hline BMV & Ole1 & Fatty acid desaturation & {$[100,101]$} \\
DENV & FASN & Fatty acid synthesis & {$[102]$} \\
DCV & SREBP & Fatty acid synthesis & {$[103]$} \\
WNV & 3-HMG-CoA reductase & Cholesterol synthesis & {$[90]$} \\
TBSV & Erg25, SMO1, SMO2 & Sterol synthesis & {$[104]$} \\
& INO2 & Regulation of phospholipid synthesis & {$[105]$} \\
HCV & PI4KIII $\alpha$ & Synthesis of PI4P & {$[106,107]$} \\
PV, CVB3, AiV & PI4KIII $\beta$ & Synthesis of PI4P & {$[93,108,109]$} \\
\hline
\end{tabular}

Abbreviations used in this Table: AiV, Aichi virus; BMV: brome mosaic virus, CVB3, coxsackievirus B3; DCV, Droshophila C virus; DENV, Dengue virus; Erg25, ergosterol enzyme 25; FASN, fatty acid synthase; HCV, Hepatitis C virus; 3-HMG-CoA reductase, 3-hydroxy-methyglutaryl-CoA reductase; INO2, inositol-1-phosphate synthase 2; Ole1, Delta(9) fatty acid desaturase; PI4KIII $\alpha$ and $\beta$, phosphatidylinositol 4-kinase class III $\alpha$ and $\beta$; PI4P, phosphatidylinositol 4-phosphate; PV, poliovirus; SMO1 and 2, sterol4 $\alpha$-methyl-oxidase 1 and 2; SREBP, sterol regulatory element binding protein; TBSV, tomato bushy stunt virus; WNV, West Nile virus.

Table 2. Examples of host cell genes associated to lipid metabolism and involved in viral replication

associated to the infection of animal pathogens like African swine fever virus [115]. On the other hand, sterols have been involved in the replication of plant pathogens, for example tomato bushy stunt virus (TBSV) [104]. Due to the high diversity of viruses that exploit the cholesterol biosynthetic pathway for replication, this could consider a common requirement. However, replication of viruses may rely on lipids other than cholesterol, as described for the alphanodavirus flock house virus (FHV) [116].

Another major class of lipids that has been related to viral replication are the fatty acids, whose metabolism has been shown to be required for the multiplication of viruses such as brome mosaic virus (BMV) [100,101], Droshophila C virus (DCV) [103], CVB3 [117], and PV [118]. In some cases, in addition to the dependence of cholesterol (discussed in the previous paragraph), viral multiplication is also dependent on fatty acid synthesis. Examples of viruses sharing both cholesterol and fatty acid requirements include DENV [102], WNV [81,102], and HCV [8,112]. Indeed, during DENV infection, the key enzyme responsible for fatty acid synthesis, the fatty acid synthase (FASN), is recruited to the viral replication complex by direct interaction with the viral protein NS3, enhancing its activity [102]. Dependence of DENV replication on fatty acids is shared by mammalian and mosquito host cells [9]. Even more, DENV modulates lipid metabolism through induction of a form of autophagy that targets lipid droplet stores, promoting the depletion of cellular triglycerides and the release of fatty acids. This results on an increase in $\beta$-oxidation and ATP production that stimulate viral replication $[1,5]$. Infection with other viruses (HCV or CVB3) also relies on fatty acids and results in an increase on FASN expression $[117,119]$, a phenomenon that does not occur upon DENV or WNV infection [81,102].

Besides cholesterol and fatty acids, specific phospholipids can also play a key role in viral replication. For instance, replication of TBSV and FHV is dependent on phospholipid biosynthesis [105]. Replication of FHV was initially associated to glycerophospholipids, being independent of cholesterol or sphingomyelin (a membrane phospholipid that is not derived from glycerol) [116]. However, recent advances on the biology of FHV indicate that 
its replication is based on the outer mitochondrial membrane and is dependent on the anionic phospholipid cardiolipin, which is almost exclusive of these membranes [120]. In this regard, more than 20 years ago, phospholipids were already associated to the replication of PV, a member of the Picornaviridae family [121]. More recently, this relationship has been confirmed after the identification of a specific phospholipid, the phosphatidylinositol 4 phosphate (PI4P), as a key component of PV replication complexes [93]. Requirement of PI4P is shared by other members of the Picornaviridae family - CVB3, Aichi virus (AiV), bovine kubovirus, and human rhinovirus 14 [93,108,109,122]- and also by viruses from other families, i.e. HCV [93,106,107,123-126]. All these viruses can specifically recruit different isoforms of the enzyme that drives the formation of PI4P from phosphatidylinositol, the phosphatidylinositol 4-kinase class III (PI4KIII) $\alpha$ or $\beta$, to their replication complexes. For instance, HCV recruits the lipid kinase PI4KIII $\alpha$ by direct interaction with viral protein NS5A [125,127], while in picornaviruses, the recruitment of PI4KIII $\beta$ can be mediated by the interaction of viral protein $3 \mathrm{~A}$ with a third cellular partner associated to the viral replication complex, ABC3D (acyl-coenzyme A binding domain containing 3) [108] or other proteins implicated in the secretory pathway [93]. The dependence on either PI4KIII $\alpha$ or $\beta$ isoforms varies between viruses. Replication of picornaviruses is specifically associated to PI4P synthesized by PI4KIII $\beta$ [93,108,109,122], while replication of HCV has been mainly associated to the function of PI4KIII $\alpha[106,107]$, and in a lower extent to PI4KIII $\beta[93,126]$. In any case, PI4P is not universally required among viruses, since the replication of the flaviviruses (WNV and DENV), and the pestivirus bovine viral diarrhea virus (all members of the Flaviviridae family, like HCV) has been shown to be independent of PI4P $[81,106,125]$.

\subsubsection{Lipid functions associated to viral genome replication}

The presence of specific lipids in the viral replication complex can accomplish with several missions. For instance, post-translational modification of viral proteins by lipids is associated to viral replication functions [128,129]. Table 3 displays representative examples of lipid functions during viral replication.

\begin{tabular}{llll}
\hline Virus & Lipid & Function & Refs. \\
\hline BMV & fatty acids & Increase in membrane plasticity and fluidity & {$[100,101]$} \\
DENV & fatty acids & Energy production to support viral replication & {$[5]$} \\
PV & PI4P & Anchor of viral replicase to replication complex & {$[93]$} \\
FHV & cardiolipin & Anchor of viral replicase to replication complex & {$[120]$} \\
HCV & sphingomyelin & Activation of RNA polymerase activity & {$[130]$} \\
WNV & cholesterol & Innate immune evasion & {$[90]$} \\
\hline
\end{tabular}

Abbreviations used in this table: BMV, brome mosaic virus; HCV, hepatitis C virus; DENV, Dengue virus; FHV, flock house virus; PI4P, phosphatidylinositol 4-phosphate; PV, poliovirus; WNV, West Nile virus.

Table 3. Examples of lipid roles during viral replication

Lipids can contribute to viral replication by acting as scaffolding molecules to anchor viral proteins. In PV, location of specific phospholipids (PI4P) to the viral replication sites 
mediates direct recruitment of the RNA dependent RNA polymerase (the enzyme that replicates the viral genome), which specifically interacts with this lipid [93]. The RNA polymerase of FHV also interacts with a specific phospholipid, the cardiolipin located on the outer mitochondrial membrane, where its replication takes place [120]. In addition to these examples, different events related to the replication of viral genomes are also influenced by specific phospholipids [131,132]. The activation of HCV replication due to a direct binding of sphingomyelin to HCV RNA polymerase has also been documented [130].

Proper topology of viral replication complexes usually depends on the induction of a membrane curvature, which may require the presence of specific proteins [133]. Membrane curvature can also be induced by modification of its lipid structure, either through changes in the polar head group or in the acyl chain composition [2,134]. Thus, during BMV infection, the function of an allele of delta9 fatty acid desaturase, an enzyme that introduces double bond in unsaturated fatty acids, has been associated to viral replication complex assembly to increase membrane fluidity and plasticity $[100,101]$. The accumulation of coneshaped lipids, such as lysophospholipids, which contain single acyl chain per phospholipid molecule, and of special lipids like cholesterol or cardiolipin, has been associated with alterations on the membrane curvature and plasticity that can contribute to replication complex assembly [1,2,135].

As commented before, the membrane rearrangements resulting from replication complex assembly can also contribute to evade the cellular immune response by hiding viral components from pathogen sensors of the innate immune machinery. Thus, WNV-induced redistribution of cellular cholesterol contributes to down regulate the interferon-stimulated antiviral signalling response to infection [90].

Finally, the reorganization of cellular lipid metabolism during infection can also contribute to the generation of ATP in order to provide energy to support robust viral replication $[1,5]$.

\subsection{Lipids and viral morphogenesis}

Most enveloped-viruses acquire their lipid membrane by budding through a cellular membrane that can be provided by different sources. For instance, flaviviruses (i.e. DENV or WNV) bud into the endoplasmic reticulum for acquisition of their envelope [80,82], while VSV (Figure 3), influenza, or HIV acquire their envelope by budding from plasma membrane [136-139]. In other cases, different cellular organelles can contribute with distinct membranes to virus envelopment, is reported for herpersvirus and poxvirus [140-142]. Viruses can take advantage of specific parts of the membrane for their assembly. Cholesterol and lipid raft microdomains play an important role on the assembly of a variety of viruses [136-138,143]. In HIV, the presence of $\mathrm{PI}(4,5) \mathrm{P}_{2}$ on the membrane is also necessary for assembly and budding of viral particles, and the viral protein Gag localizes to assembly sites via the interaction with this lipid [144]. The synthesis of fatty acids has also been associated to the envelopment of viruses [6].

Other cellular lipid structures play a role on the assembly of a number of viruses. Thus, of intracellular lipid droplets have been associated with the assembly and morphogenesis 

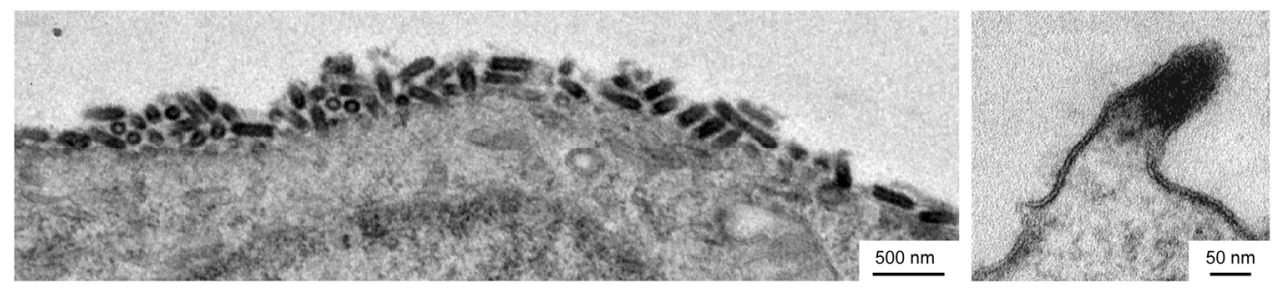

Figure 3. Virus budding through the plasma membrane. Images correspond to BHK-21 cells infected with the rhabdovirus VSV, fixed, and processed for transmission electron microscopy at $7 \mathrm{~h}$ postinfection. For technical details related to virus infection and sample preparation see [145].

of DENV and HCV $[78,79,146]$. Assembly of HCV particles occurs on the surface of lipid droplets and, as mentioned earlier, it is related to the very low density lipoprotein (VLDL) pathway, a phenomenon that leads to the formation of unique lipo-viro-particles $[4,147]$. The lipoprotein component associated to HCV particles is essential for their infectivity [148], since one of its functions is to interact with LDL-R, thus contributing to viral attachment (section 2.1.1).

Lipids incorporated to viral proteins due to post-translational modifications are also involved in crucial steps of enveloped virus assembly $[149,150]$. Regarding morphogenesis of non-enveloped viruses, myristoylation of VP4 protein of PV and FMDV has been shown necessary for proper capsid assembly [151,152].

\subsubsection{Lipid composition of enveloped viruses}

Differences on the lipid composition of the viral membranes may reflect their different origin. Despite that the lipid content of enveloped viruses has been studied for decades [153155], quantitative analyses of viral lipidomes (the entire content of lipids) at the individual molecular species level have not been possible until recently, by means of the improvement of mass spectrometry [3,139]. Following this approach, several studies have extended the knowledge on viral lipid composition. Nevertheless, drawbacks associated to the purification of cellular membranes, in particular the plasma membrane, still complicate the analysis of lipid sorting during viral budding [3].

As commented above, viral membranes can be originated from varied cellular sources (section 2.3). The lipid composition of both Semliki Forest virus (SFV) and VSV is indistinguishable and only displays slight differences with that of the plasma membrane [139]. Being SFV and VSV from different viral families (Togaviridae and Rhabdoviridae, respectively), these viruses constitute an example of little selection of the lipids included in their envelopes. Since the composition of the viral envelopes of both viruses is similar to that of the plasma membrane, the small differences observed between plasma membrane and these viral envelopes could be explained by the enrichment in specific lipids to facilitate the membrane curvature required for viral budding [139].

In the case of retroviruses (i.e. HIV and murine leukaemia virus), the overall lipid composition of viral envelopes resembles that of detergent-resistant membrane 
microdomains [156,157]. An enrichment in $\mathrm{PI}(4,5) \mathrm{P}_{2}$ has also been documented in HIV envelope, which is compatible with the dependence on the interaction between the viral protein Gag and this lipid to promote HIV budding from plasma membrane [157]. Another virus that buds from membrane rafts is influenza virus [138]. The lipidome of this virus has been analyzed for viruses budding from the apical membrane of polarized cells [158]. This study revealed that that the apical cellular membrane was enriched in sphingolipids and cholesterol, whereas glycerophospholipids were reduced, and storage lipids were depleted compared with the whole-cell membranes. These results are consistent with an accumulation of lipid rafts at the membranes where the virus buds. In addition, the virus membrane exhibited a further enrichment of sphingolipids and cholesterol when compared with the donor membrane at the expense of phosphatidylcholines [158].

In other cases, major differences in lipid content between viral envelopes and host cell membranes have been found. An interesting example is the envelope of HCMV, which contains more phosphatidylethanolamines and less phosphatidylserines than the host cell membranes, resembling the synaptic vesicle lipidome [159]. Another virus with marked differences with cellular membranes is $\mathrm{HCV}$, whose particles show a unique lipid composition in comparison with all other viruses analyzed to date. In addition, the lipid content of the HCV envelope is also different from that of the cells in which it was produced (cholesteryl esters comprise almost half of the total HCV lipids), resembling the composition of VLDL and LDL [160]. This finding is compatible with the association of HCV assembly with the VLDL pathway that leads to the formation of lipo-viro-particles [4,147].

\section{Targeting lipid metabolism, a novel antiviral strategy}

Specific lipids are essential for multiple steps of the viral replication cycle and, therefore, different strategies can be used to interfere with virus infection. As a first approach to inhibit enveloped virus multiplication, the functions of lipids incorporated into the viral particle can be targeted by chemical compounds or even by antibodies [161]. This is the case of broad-spectrum antivirals, - some of them already licensed for human use, such as arbidol [162-164] -, or inhibitors of membrane fusion [3]. Impairment of viral fusion can be achieved also by targeting viral machinery involved in this process, a strategy currently assayed for HIV treatment [165].

An alternative, non-excluding lipid-targeted strategy to prevent viral multiplication is based on inhibitors of enzymes that catalyse lipid metabolic fluxes upregulated by viral infections [6]. Examples of compounds that act at distinct points of lipid metabolism and with reported antiviral activity in vitro are given in Table 4 . Targeting lipid metabolism as an antiviral strategy raises important concerns. On one hand, alteration of such important metabolic pathway for cellular homeostasis may resemble a non-specific strategy, which could result in deleterious effects for the host. However, it should be also considered that currently antiviral compounds also target other major metabolic pathways, i.e. that of nucleic acids metabolism [166-169]. On the other hand, targeting host factors to avoid viral replication could also carry advantages. Drugs that target host factors seem to be less susceptible to the 
development of viral resistance than strategies focused on viral proteins. Another advantage of this approach is that compounds targeting a specific group of lipids can successfully inhibit replication of different unrelated viruses (Table 4), thus constituting candidates for broad-spectrum antiviral drugs. These facts make that the use of drugs that impair different aspects of lipid metabolism has been proposed as a feasible antiviral approach $[1,6,14]$.

\begin{tabular}{llll}
\hline Target lipid & Inhibitor & Antiviral activity against & Refs. \\
\hline Cholesterol & Statins & HIV, HCV, influenza & {$[170-176]$} \\
& U18666A & DENV, HCV & {$[113,177]$} \\
Fatty acids & TOFA & HCMV, Influenza & {$[6]$} \\
& C75 & HCMV, DENV, YFV, WNV, Influenza, HCV, CVB3 & {$[6,9,81,102,117,119]$} \\
& Cerulenin & DENV, WNV, PV, CVB3 & {$[81,102,117,121]$} \\
& Arachidonate & HCV & {$[178]$} \\
& Oleic acid & PV & {$[118]$} \\
PI4P & Enviroxime- & PV, AiV & {$[108,109]$} \\
& like & & {$[81,93,109]$} \\
& PIK93 & PV, CVB3, CVB5 & {$[179]$} \\
Sphingolipids & AL-9 & HCV & {$[180-182]$} \\
Multiple & Valproic acid & Hepatitis B virus, HCV & VACV, WNV, SFV, SINV, ASFV, VSV, LCMV, $[145]$ \\
& & USUV & \\
\hline
\end{tabular}

Abbreviations used in this table: AiV, Aichi virus; ASFV, African swine fever virus; CVB, coxsackievirus B; C75, trans4-carboxy-5-octyl-3-methylene-butyrolactone; DENV, Dengue virus; HCMV, human cytomegalovirus; HCV, hepatitis $C$ virus; HIV, human immunodeficiency virus; LCMV, lymphocytic chioriomeningitis virus; PV, poliovirus; SINV, Sindbis virus; SFV, Semliki Forest virus; TOFA, 5-tetradecyloxy-2-furoic acid; USUV, Usutu virus; VACV, vaccinia virus; VSV, vesicular stomatitis virus; WNV, West Nile virus; YFV, yellow fever virus

Table 4. Examples of drugs targeting lipid metabolism with reported antiviral activity

\subsection{Targeting cholesterol as an antiviral strategy}

Cholesterol is involved in multiple steps of the viral cycle. Impairment of cholesterol biosynthetic pathway by inhibitors of 3-hydroxy-3-methyl-glutaryl-CoaA reductase (3HMG-CoA reductase) like statins, commonly used in treatment of cardiovascular disease, constitutes a novel antiviral approach $[174,175,183]$. The clinical success of these inhibitors for human disorders also indicates that inhibitors of lipid metabolism can be safe and effective for human therapy. An additional effect of the treatment with statins, unrelated to the inhibition of 3-HMG-CoA reductase, is the inhibition of the binding of leukocyte function-associated antigen-1 (LFA-1) to the intercellular adhesion molecule (ICAM-1) [184], thus being immunomodulators and anti-inflammatory agents $[185,186]$. These properties can carry additional advantages for fighting HIV [174-176].

The infection with the paramyxovirus respiratory syncitial virus (RSV) is dependent on the isoprenylation at the carboxy terminus of the cellular protein RhoA by geranylgeranyltransferase. Lovastatin, which blocks prenylation pathways in the cell by directly inhibiting 3-HMG-CoA reductase, inhibits RSV infection both in cultured cells and in mice [183]. Treatment of patients with different statins (i.e. lovastatin, simvastin, or 
fluvastin) resulted in diverse effects on $\mathrm{HCV}$ infection, ranging from an absence of antiviral effect to a modest improvement of sustained antiviral response, or a reduction of viremia [172,173,187-189]. Beneficial effects derived from treatment with statins of infection with diverse influenza strains have also been reported in animal models and human studies [170,171], although other studies do not support these conclusions [190].

Targeting cholesterol in viral infection can be achieved using drugs other than statins, for instance U18666A. This is an intracellular cholesterol transport inhibitor widely used to block the intracellular trafficking of cholesterol and mimic Niemann-Pick type C disease, which also blocks cholesterol biosynthesis by inhibiting oxidosqualene cyclase and desmosterol reductase [191]. Treatment with U18666A inhibits DENV infection in cultured cells, and the effect of this compound is additive to the inhibitory effect of C75 (an inhibitor of FASN), which shows that both, cholesterol and fatty acids, are required for successful DENV replication [177]. U18666A also displays an antiviral effect against HCV infection and a synergistic effect has been reported when combined with interferon [113].

\subsection{Inhibitors of fatty acid biosynthesis as potential antiviral compounds}

The biosynthesis of fatty acids plays an important role for multiplication of a wide variety of viruses $[6,9,81,102]$. Pharmacological inhibition of this metabolic pathway can be achieved using 5-tetradecyloxy-2-furoic acid (TOFA), an inhibitor of acetyl-CoA carboxylase (ACC) [192]. Treatment with this compound has been shown to block replication of HCMV and influenza A virus [6]. Although the results derived from these experiments performed in model cell culture systems need to be further reproduced using animal models, the concentrations of TOFA that successfully inhibit HCMV infection in cultured cells are in the range of plasma concentrations found in rats treated with this inhibitor [6]. In $\mathrm{HCV}$, treatment with TOFA attenuates the enhancement of replication of $\mathrm{HCV}$ induced by ethanol [193].

On the other hand, treatment with trans-4-carboxy-5-octyl-3-methylene-butyrolactone (C75) - an inhibitor of FASN, the key enzyme of fatty acid biosynthetic pathway - also resulted in inhibition of the replication of both HCMV and influenza A virus [6]. These experiments were performed in cultured cells, and the concentrations of the inhibitor tested did not induce host cell toxicity or apoptosis [6]. Similar results have been obtained for DENV, yellow fever virus (YFV), WNV, and HCV using the FASN inhibitor C75 [9,81,102,119], or cerulenin, another FASN inhibitor [81,102,111]. HMCV, influenza A, DENV, YFV, and WNV are enveloped viruses. The antiviral effect of either cerulenin or C75 has also been probed for the non-enveloped viruses CVB3 and PV [117,121], enlarging the potential antiviral spectrum of FASN inhibitors. However, it should be noted that blockage of FASN by C75 can cause severe anorexia and weight loss in animal models [194]. This makes of C75 a drug not aimed for human use, although it has aided to the identification of potential pathways to target obesity [195], and is also contributing to the understanding of the relationship between biosynthetic fatty acid synthesis and viral multiplication [6,9,81,102,117]. For DENV, a direct interaction between the viral protein NS3 and FASN has been reported 
[102]. Inhibition of this interaction could contribute to the design of antivirals to fight this important human disease.

Infection of $\mathrm{HCV}$ is intimately connected to lipid metabolism, including the fatty acid biosynthetic pathway [4,8], and its replication can be inhibited by C75 [119]. Indeed, fatty acids can either stimulate or inhibit HCV replication, depending on their degree of saturation [112]. Arachidonate, a polyunsaturated fatty acid, also inhibits HCV replication [112] via the lipid peroxidation induced by reactive oxygen species (ROS) derived from $\mathrm{HCV}$ replication that converts polyunsaturated fatty acids into reactive carbonyls that inactivate proteins [178]. These events can be prevented by treatment with the antioxidant vitamin E [178]. As a result of the connections between fatty acids and cholesterol biosynthetic pathways, inhibition of fatty acid synthesis can be also related to the reduction of the infection of $\mathrm{HCV}$, through inhibition of the geranylgeranylation of cellular factors required for HCV replication [112,196]. The use of unsaturated fatty acids has also been applied to block myristoylation of HIV Gag protein to prevent virus budding [150].

\subsection{Phosphlipids as antiviral targets}

Viral replication also relies on phospholipid biosynthesis [105,121]. This makes drugs interfering this pathway candidates for antiviral design. Along this line, the antiviral properties of valproic acid - a short chain fatty acid commonly used for the treatment of epilepsy and bipolar disorder that impairs multiple aspects of phosphoinositide metabolism [197-199] - against a broad panel of enveloped viruses have been reported (Table 4) [145].

Treatment with a chimeric antibody directed against phospahtidylserine can cure arenavirus and cytomegalovirus infections in animal models [200]. The mechanism of action of this therapy is based on the exposure of phosphatidylserine on the external leaflet of the plasma membrane, a preapoptotic event in cells infected by a broad variety of viruses. The safety and pharmacokinetics of this antibody have been already evaluated in clinical trials for treatment of other human disorders [201]. Another example of the use of antiphospholipidantibodies to combat a viral disease is provided by HIV, since different antiphospholipid antibodies have shown a broad neutralizing activity against this virus [161].

Recent reports have highlighted the role of a specific phospholipid species, PI4P, in the replication of enteroviruses (PV, CVB3) and HCV (section 2.2.2). The synthesis of PI4P associated to viral replication relies on the function of the cellular enzymes PI4KIII $\alpha$ and $\beta$. This makes both lipid kinases potential drug targets for antiviral design. An inhibitor of PI4KIII $\beta$, PIK93 [202], has been shown to impair replication of enteroviruses [81,93,109]. Related reports have also uncovered that this enzyme is the cellular target of known antiviral compounds against enteroviruses [109]. This is so for some enviroxime-like compounds - T-00127-HEV1 and GW5074 [93] - that integrate a group of antivirals that inhibits enterovirus replication, for which mutations conferring drug resistance mapped to the same region of the enteroviral protein 3A [109,203-205]. The recruitment of PI4KIII $\beta$ to viral replication complexes requires the participation of cellular partners like the Golgi adaptor protein acyl coenzyme A (acyl-CoA) binding domain protein 3 (ACBD3/GPC60), as 
described for $\mathrm{AiV}[108,122]$. In this way, modulation of the interaction between these proteins could also constitute a novel antiviral strategy [122].

In HCV infection the isoform of the enzyme involved in viral replication is mainly PI4KIII $\alpha$ $[106,107]$, although a role of the $\beta$ isoform in the inhibition of HCV replication due to treatment with PIK93 has also been reported [126]. Consistent with these findings, specific compounds that successfully inhibit PV replication through blockage of PI4KIII $\beta$ (GW5074 and T-00127-HEV1) do not affect HCV replication, although other enviroxime-like compounds can affect both enteroviral and HCV replication [109]. On the other hand, 4anilino quinazolines were first reported to have antiviral activity against $\mathrm{HCV}$, although the mechanism was not well defined. However, a recent study has associated the antiviral activity of a representative 4-anilino quinazoline (AL-9) with the inhibition of PI4KIII $\alpha$ during HCV infection, which opens new therapeutic approaches [179]. Since the viral protein NS5A directly interacts with PI4KIII $\alpha$ during HCV infection [125,127], modulation of this interaction also raises novel possibilities for antiviral research.

Overall, these examples of drugs targeting different enzymes related to phosphoinositide metabolism support this strategy as a feasible approach for antiviral drug discovery. In this line, related phosphoinositide kinases constitute an important emerging class of drug targets [202].

\subsection{Sphingolipids as antiviral targets}

Sphingolipids constitute a major component of lipid rafts [37,38], which, as commented before, are involved in different steps of viral infection, making sphingolipids potential antiviral targets. Along this line, ebolavirus requires the activity of acid sphingomyelinase, the enzyme that converts sphingomyelin to phosphocholine and ceramide for infection, and depletion of sphingomyelin reduces its infection [206]. A dependence on sphingomyelin for HCV replication has also been documented [130]. Inhibition of serine palmitoyltransferase, the enzyme that catalyzes the first step on sphingolipid biosynthesis, using myriocin has also been assayed against HCV or hepatitis B virus, either alone or in combination with interferon [180-182]. However, a certain controversy exists regarding whether the inhibitory effect of myriocin on HCV replication is attributable to the specific inhibition of serine palmitoyltransferase, since FTY720, a compound that like myriocin is structurally similar to sphingosine but does not inhibit serine palmitoyltransferase, also inhibits HCV replication [207].

\section{Conclusion}

The analysis of the functions of cellular factors in viral infections has highlighted the role of different lipid species in these infections. Viruses can use cellular lipids like bricks to build viral particles or to develop viral replication complexes, thus facilitating its multiplication. But viruses can also manipulate host cell metabolism towards the production of specific lipid species, unveiling an intimate relationship between viruses and host cell lipid 
metabolism. Indeed, great progresses have been recently made in this area due to the identification of specific lipids as key factors for viral multiplication. However, the specific function of most of these lipids remains to be determined. A better understanding of the interactions between viral infections and lipid metabolism is desirable to asses the roles of lipids in viral multiplication. This knowledge could lead to the identification of lipid targets and druggable metabolic pathways suitable for antiviral development. Lipid candidates for these interventions have already been identified, for instance fatty acids, cholesterol or specific phospholipids. Indeed, initial lipid-based antiviral approaches have been already started, even at clinical level (i.e. statins). This example has probed that drugs already licensed for humans that act at different points of lipid metabolism can constitute potential candidates to fight viral diseases. These lipid-targeted antiviral approaches could be exclusive or could also be complementary to other antiviral therapies already available.

As recently remarked, 'if RNA ruled the last decade and DNA dominated the previous one, could the next decade be the one for lipids?' [208]. The new advances on the knowledge of the interplay between viruses and lipids evidence that the answer to this question could be 'Yes' in the case of virology [1]. Hopefully, we are now assisting to the promising birth of a novel lipid-based branch of antiviral research focused on this challenging and still poorly explored field for drug discovery.

\section{Author details}

Miguel A. Martín-Acebes, Ángela Vázquez-Calvo, Flavia Caridi and Francisco Sobrino Department of Virology and Microbiology, Centre for Molecular Biology "Severo Ochoa" (CBMSO) (UAM/CSIC), Cantoblanco, Madrid, Spain

Juan-Carlos Saiz Department of Biotechnology, National Institute for Food Science and Technology (INIA), Madrid, Spain

\section{Acknowledgement}

Work at CBMSO was supported by grants from Ministerio de Ciencia e Innovación (MICINN, Spain) BIO2008-0447-C03-01, and BIO2011-24351, and by an institutional grant from the "Fundación Ramón Areces".

Work at INIA was supported by grants RTA2011-00036 from the Spanish Ministerio de Ciencia e Innovación (MICINN) and the Network of Animal Disease Infectiology and Research-European Union NADIR-EU-228394. MAMA is the recipient of a JAE-Doc fellowship from Spanish Research Council (CSIC).

\section{References}

[1] Heaton NS, Randall G (2011) Multifaceted roles for lipids in viral infection. Trends Microbiol 19: 368-375. 
[2] Stapleford KA, Miller DJ (2010) Role of cellular lipids in positive-sense RNA virus replication complex assembly and function. Viruses 2: 1055-1068.

[3] Lorizate M, Krausslich HG (2011) Role of lipids in virus replication. Cold Spring Harb Perspect Biol 3: a004820.

[4] Alvisi G, Madan V, Bartenschlager R (2011) Hepatitis C virus and host cell lipids: an intimate connection. RNA Biol 8: 258-269.

[5] Heaton NS, Randall G (2010) Dengue virus-induced autophagy regulates lipid metabolism. Cell Host Microbe 8: 422-432.

[6] Munger J, Bennett BD, Parikh A, Feng XJ, McArdle J, Rabitz HA, Shenk T, Rabinowitz JD (2008) Systems-level metabolic flux profiling identifies fatty acid synthesis as a target for antiviral therapy. Nat Biotechnol 26: 1179-1186.

[7] Blackham S, Baillie A, Al-Hababi F, Remlinger K, You S, Hamatake R, McGarvey MJ (2010) Gene expression profiling indicates the roles of host oxidative stress, apoptosis, lipid metabolism, and intracellular transport genes in the replication of hepatitis $\mathrm{C}$ virus. J Virol 84: 5404-5414.

[8] Targett-Adams P, Boulant S, Douglas MW, McLauchlan J (2010) Lipid metabolism and HCV infection. Viruses 2: 1195-1217.

[9] Perera R, Riley C, Isaac G, Hopf-Jannasch AS, Moore RJ, Weitz KW, Pasa-Tolic L, Metz TO, Adamec J, Kuhn RJ (2012) Dengue virus infection perturbs lipid homeostasis in infected mosquito cells. PLoS Pathog 8: e1002584.

[10] Rodgers MA, Saghatelian A, Yang PL (2009) Identification of an overabundant cholesterol precursor in hepatitis B virus replicating cells by untargeted lipid metabolite profiling. J Am Chem Soc 131: 5030-5031.

[11] Diamond DL, Syder AJ, Jacobs JM, Sorensen CM, Walters KA, Proll SC, McDermott JE, Gritsenko MA, Zhang Q, Zhao R, Metz TO, Camp DG, 2nd, Waters KM, Smith RD, Rice CM, Katze MG (2010) Temporal proteome and lipidome profiles reveal hepatitis C virus-associated reprogramming of hepatocellular metabolism and bioenergetics. PLoS Pathog 6: e1000719.

[12] Miller S, Krijnse-Locker J (2008) Modification of intracellular membrane structures for virus replication. Nat Rev Microbiol 6: 363-374.

[13] den Boon JA, Diaz A, Ahlquist P (2010) Cytoplasmic viral replication complexes. Cell Host Microbe 8: 77-85.

[14] Bassendine MF, Sheridan DA, Felmlee DJ, Bridge SH, Toms GL, Neely RD (2011) HCV and the hepatic lipid pathway as a potential treatment target. J Hepatol 55: 1428-1440.

[15] Nagy PD, Pogany J (2012) The dependence of viral RNA replication on co-opted host factors. Nat Rev Microbiol 10: 137-149.

[16] Sandvig K, van Deurs B (2008) Cell biology: Viruses in camouflage. Nature 453: 466-467.

[17] Schlegel R, Tralka TS, Willingham MC, Pastan I (1983) Inhibition of VSV binding and infectivity by phosphatidylserine: is phosphatidylserine a VSV-binding site? Cell 32: 639-646. 
[18] Matsuo H, Chevallier J, Mayran N, Le Blanc I, Ferguson C, Faure J, Blanc NS, Matile S, Dubochet J, Sadoul R, Parton RG, Vilbois F, Gruenberg J (2004) Role of LBPA and Alix in multivesicular liposome formation and endosome organization. Science 303: 531-534.

[19] Le Blanc I, Luyet PP, Pons V, Ferguson C, Emans N, Petiot A, Mayran N, Demaurex N, Faure J, Sadoul R, Parton RG, Gruenberg J (2005) Endosome-to-cytosol transport of viral nucleocapsids. Nat Cell Biol 7: 653-664.

[20] Campanero-Rhodes MA, Smith A, Chai W, Sonnino S, Mauri L, Childs RA, Zhang Y, Ewers H, Helenius A, Imberty A, Feizi T (2007) N-glycolyl GM1 ganglioside as a receptor for simian virus 40. J Virol 81: 12846-12858.

[21] Anderson HA, Chen Y, Norkin LC (1996) Bound simian virus 40 translocates to caveolin-enriched membrane domains, and its entry is inhibited by drugs that selectively disrupt caveolae. Mol Biol Cell 7: 1825-1834.

[22] Zaitseva E, Yang ST, Melikov K, Pourmal S, Chernomordik LV Dengue virus ensures its fusion in late endosomes using compartment-specific lipids. PLoS Pathog 6: e1001131.

[23] Mercer J, Helenius A (2008) Vaccinia virus uses macropinocytosis and apoptotic mimicry to enter host cells. Science 320: 531-535.

[24] Ewers H, Helenius A (2011) Lipid-mediated endocytosis. Cold Spring Harb Perspect Biol 3: a004721.

[25] Low JA, Magnuson B, Tsai B, Imperiale MJ (2006) Identification of gangliosides GD1b and GT1b as receptors for BK virus. J Virol 80: 1361-1366.

[26] Tsai B, Gilbert JM, Stehle T, Lencer W, Benjamin TL, Rapoport TA (2003) Gangliosides are receptors for murine polyoma virus and SV40. Embo J 22: 4346-4355.

[27] Magaldi TG, Buch MH, Murata H, Erickson KD, Neu U, Garcea RL, Peden K, Stehle T, Dimaio D (2012) Mutations in the GM1 Binding Site of SV40 VP1 Alter Receptor Usage and Cell Tropism. J Virol.

[28] Tsai B, Qian M (2010) Cellular entry of polyomaviruses. Curr Top Microbiol Immunol 343: 177-194.

[29] Meisen I, Dzudzek T, Ehrhardt C, Ludwig S, Mormann M, Rosenbruck R, Lumen R, Kniep B, Karch H, Muthing J (2012) The human H3N2 influenza viruses A/Victoria/3/75 and A/Hiroshima/52/2005 preferentially bind to alpha2,3-sialylated monosialogangliosides with fucosylated poly-N-acetyllactosaminyl chains. Glycobiology.

[30] Izquierdo-Useros N, Lorizate M, Contreras FX, Rodriguez-Plata MT, Glass B, Erkizia I, Prado JG, Casas J, Fabrias G, Krausslich HG, Martinez-Picado J (2012) Sialyllactose in Viral Membrane Gangliosides Is a Novel Molecular Recognition Pattern for Mature Dendritic Cell Capture of HIV-1. PLoS Biol 10: e1001315.

[31] Carneiro FA, Lapido-Loureiro PA, Cordo SM, Stauffer F, Weissmuller G, Bianconi ML, Juliano MA, Juliano L, Bisch PM, Da Poian AT (2006) Probing the interaction between vesicular stomatitis virus and phosphatidylserine. Eur Biophys J 35: 145-154.

[32] Coil DA, Miller AD (2004) Phosphatidylserine is not the cell surface receptor for vesicular stomatitis virus. J Virol 78: 10920-10926. 
[33] Agnello V, Abel G, Elfahal M, Knight GB, Zhang QX (1999) Hepatitis C virus and other flaviviridae viruses enter cells via low density lipoprotein receptor. Proc Natl Acad Sci U S A 96: 12766-12771.

[34] Marsh M, Helenius A (2006) Virus entry: open sesame. Cell 124: 729-740.

[35] Conner SD, Schmid SL (2003) Regulated portals of entry into the cell. Nature 422: 37-44.

[36] Mayor S, Pagano RE (2007) Pathways of clathrin-independent endocytosis. Nat Rev Mol Cell Biol 8: 603-612.

[37] Simons K, Ikonen E (1997) Functional rafts in cell membranes. Nature 387: 569-572.

[38] Jacobson K, Mouritsen OG, Anderson RG (2007) Lipid rafts: at a crossroad between cell biology and physics. Nat Cell Biol 9: 7-14.

[39] Chinnapen DJ, Chinnapen H, Saslowsky D, Lencer WI (2007) Rafting with cholera toxin: endocytosis and trafficking from plasma membrane to ER. FEMS Microbiol Lett 266: 129-137.

[40] Martin-Belmonte F, Martinez-Menarguez JA, Aranda JF, Ballesta J, de Marco MC, Alonso MA (2003) MAL regulates clathrin-mediated endocytosis at the apical surface of Madin-Darby canine kidney cells. J Cell Biol 163: 155-164.

[41] Rollason R, Korolchuk V, Hamilton C, Schu P, Banting G (2007) Clathrin-mediated endocytosis of a lipid-raft-associated protein is mediated through a dual tyrosine motif. J Cell Sci 120: 3850-3858.

[42] Stoddart A, Dykstra ML, Brown BK, Song W, Pierce SK, Brodsky FM (2002) Lipid rafts unite signaling cascades with clathrin to regulate BCR internalization. Immunity 17: 451-462.

[43] Bender FC, Whitbeck JC, Ponce de Leon M, Lou H, Eisenberg RJ, Cohen GH (2003) Specific association of glycoprotein $\mathrm{B}$ with lipid rafts during herpes simplex virus entry. J Virol 77: 9542-9552.

[44] Damm EM, Pelkmans L, Kartenbeck J, Mezzacasa A, Kurzchalia T, Helenius A (2005) Clathrin- and caveolin-1-independent endocytosis: entry of simian virus 40 into cells devoid of caveolae. J Cell Biol 168: 477-488.

[45] Das S, Chakraborty S, Basu A Critical role of lipid rafts in virus entry and activation of phosphoinositide 3' kinase/Akt signaling during early stages of Japanese encephalitis virus infection in neural stem/progenitor cells. J Neurochem 115: 537-549.

[46] Glende J, Schwegmann-Wessels C, Al-Falah M, Pfefferle S, Qu X, Deng H, Drosten C, Naim HY, Herrler G (2008) Importance of cholesterol-rich membrane microdomains in the interaction of the $S$ protein of SARS-coronavirus with the cellular receptor angiotensin-converting enzyme 2. Virology 381: 215-221.

[47] Liao Z, Cimakasky LM, Hampton R, Nguyen DH, Hildreth JE (2001) Lipid rafts and HIV pathogenesis: host membrane cholesterol is required for infection by HIV type 1 . AIDS Res Hum Retroviruses 17: 1009-1019.

[48] Lu X, Xiong Y, Silver J (2002) Asymmetric requirement for cholesterol in receptorbearing but not envelope-bearing membranes for fusion mediated by ecotropic murine leukemia virus. J Virol 76: 6701-6709. 
[49] Huang H, Li Y, Sadaoka T, Tang H, Yamamoto T, Yamanishi K, Mori Y (2006) Human herpesvirus 6 envelope cholesterol is required for virus entry. J Gen Virol 87: 277-285.

[50] Imhoff H, von Messling V, Herrler G, Haas L (2007) Canine distemper virus infection requires cholesterol in the viral envelope. J Virol 81: 4158-4165.

[51] Sun X, Whittaker GR (2003) Role for influenza virus envelope cholesterol in virus entry and infection. J Virol 77: 12543-12551.

[52] Martin-Acebes MA, Gonzalez-Magaldi M, Sandvig K, Sobrino F, Armas-Portela R (2007) Productive entry of type C foot-and-mouth disease virus into susceptible cultured cells requires clathrin and is dependent on the presence of plasma membrane cholesterol. Virology 369: 105-118.

[53] Snyers L, Zwickl H, Blaas D (2003) Human rhinovirus type 2 is internalized by clathrinmediated endocytosis. J Virol 77: 5360-5369.

[54] Yi L, Fang J, Isik N, Chim J, Jin T (2006) HIV gp120-induced interaction between CD4 and CCR5 requires cholesterol-rich microenvironments revealed by live cell fluorescence resonance energy transfer imaging. J Biol Chem 281: 35446-35453.

[55] Coyne CB, Bergelson JM (2006) Virus-induced Abl and Fyn kinase signals permit coxsackievirus entry through epithelial tight junctions. Cell 124: 119-131.

[56] Kwiatkowska K (2010) One lipid, multiple functions: how various pools of $\mathrm{PI}(4,5) \mathrm{P}(2)$ are created in the plasma membrane. Cell Mol Life Sci 67: 3927-3946.

[57] Antonescu CN, Aguet F, Danuser G, Schmid SL (2011) Phosphatidylinositol-(4,5)bisphosphate regulates clathrin-coated pit initiation, stabilization, and size. Mol Biol Cell 22: 2588-2600.

[58] De Matteis MA, Godi A (2004) PI-loting membrane traffic. Nat Cell Biol 6: 487-492.

[59] James DJ, Khodthong C, Kowalchyk JA, Martin TF (2008) Phosphatidylinositol 4,5bisphosphate regulates SNARE-dependent membrane fusion. J Cell Biol 182: 355-366.

[60] Zoncu R, Perera RM, Sebastian R, Nakatsu F, Chen H, Balla T, Ayala G, Toomre D, De Camilli PV (2007) Loss of endocytic clathrin-coated pits upon acute depletion of phosphatidylinositol 4,5-bisphosphate. Proc Natl Acad Sci U S A 104: 3793-3798.

[61] Mercer J, Schelhaas M, Helenius A (2010) Virus entry by endocytosis. Annu Rev Biochem 79: 803-833.

[62] Barrero-Villar M, Barroso-Gonzalez J, Cabrero JR, Gordon-Alonso M, Alvarez-Losada S, Munoz-Fernandez MA, Sanchez-Madrid F, Valenzuela-Fernandez A (2008) PI4P5kinase Ialpha is required for efficient HIV-1 entry and infection of T cells. J Immunol 181: 6882-6888.

[63] Teissier E, Pecheur EI (2007) Lipids as modulators of membrane fusion mediated by viral fusion proteins. Eur Biophys J 36: 887-899.

[64] Harrison SC (2008) Viral membrane fusion. Nat Struct Mol Biol 15: 690-698.

[65] Puri A, Paternostre M, Blumenthal R (2002) Lipids in viral fusion. Methods Mol Biol 199: 61-81.

[66] Rey FA (2006) Molecular gymnastics at the herpesvirus surface. EMBO Rep 7: 10001005. 
[67] Kielian M, Chanel-Vos C, Liao M (2010) Alphavirus Entry and Membrane Fusion. Viruses 2: 796-825.

[68] Biswas S, Yin SR, Blank PS, Zimmerberg J (2008) Cholesterol promotes hemifusion and pore widening in membrane fusion induced by influenza hemagglutinin. J Gen Physiol 131: 503-513.

[69] Vazquez-Calvo A, Saiz JC, McCullough KC, Sobrino F, Martin-Acebes MA (2012) Aciddependent viral entry. Virus Res. In press

[70] Roth SL, Whittaker GR (2011) Promotion of vesicular stomatitis virus fusion by the endosome-specific phospholipid bis(monoacylglycero)phosphate (BMP). FEBS Lett 585: 865-869.

[71] Moesker B, Rodenhuis-Zybert IA, Meijerhof T, Wilschut J, Smit JM (2010) Characterization of the functional requirements of West Nile virus membrane fusion. J Gen Virol 91: 389-393.

[72] Bhattacharya B, Roy P (2010) Role of lipids on entry and exit of bluetongue virus, a complex non-enveloped virus. Viruses 2: 1218-1235.

[73] Trask SD, Guglielmi KM, Patton JT (2010) Primed for Discovery: Atomic-Resolution Cryo-EM Structure of a Reovirus Entry Intermediate. Viruses 2: 1340-1346.

[74] Hassan SH, Wirblich C, Forzan M, Roy P (2001) Expression and functional characterization of bluetongue virus VP5 protein: role in cellular permeabilization. J Virol 75: 8356-8367.

[75] Danthi P, Tosteson M, Li QH, Chow M (2003) Genome delivery and ion channel properties are altered in VP4 mutants of poliovirus. J Virol 77: 5266-5274.

[76] Krauzewicz N, Streuli CH, Stuart-Smith N, Jones MD, Wallace S, Griffin BE (1990) Myristylated polyomavirus VP2: role in the life cycle of the virus. J Virol 64: 4414-4420.

[77] Mackenzie J (2005) Wrapping things up about virus RNA replication. Traffic 6: 967-977.

[78] Samsa MM, Mondotte JA, Iglesias NG, Assuncao-Miranda I, Barbosa-Lima G, Da Poian AT, Bozza PT, Gamarnik AV (2009) Dengue virus capsid protein usurps lipid droplets for viral particle formation. PLoS Pathog 5: e1000632.

[79] Miyanari Y, Atsuzawa K, Usuda N, Watashi K, Hishiki T, Zayas M, Bartenschlager R, Wakita T, Hijikata M, Shimotohno K (2007) The lipid droplet is an important organelle for hepatitis C virus production. Nat Cell Biol 9: 1089-1097.

[80] Welsch S, Miller S, Romero-Brey I, Merz A, Bleck CK, Walther P, Fuller SD, Antony C, Krijnse-Locker J, Bartenschlager R (2009) Composition and three-dimensional architecture of the dengue virus replication and assembly sites. Cell Host Microbe 5: 365-375.

[81] Martin-Acebes MA, Blazquez AB, Jimenez de Oya N, Escribano-Romero E, Saiz JC (2011) West nile virus replication requires Fatty Acid synthesis but is independent on phosphatidylinositol-4-phosphate lipids. PLoS One 6: e24970.

[82] Mackenzie JM, Westaway EG (2001) Assembly and maturation of the flavivirus Kunjin virus appear to occur in the rough endoplasmic reticulum and along the secretory pathway, respectively. J Virol 75: 10787-10799. 
[83] Moradpour D, Gosert R, Egger D, Penin F, Blum HE, Bienz K (2003) Membrane association of hepatitis $C$ virus nonstructural proteins and identification of the membrane alteration that harbors the viral replication complex. Antiviral Res 60: 103109.

[84] Martin-Acebes MA, Gonzalez-Magaldi M, Rosas MF, Borrego B, Brocchi E, ArmasPortela R, Sobrino F (2008) Subcellular distribution of swine vesicular disease virus proteins and alterations induced in infected cells: a comparative study with foot-andmouth disease virus and vesicular stomatitis virus. Virology 374: 432-443.

[85] Suhy DA, Giddings TH, Jr., Kirkegaard K (2000) Remodeling the endoplasmic reticulum by poliovirus infection and by individual viral proteins: an autophagy-like origin for virus-induced vesicles. J Virol 74: 8953-8965.

[86] Hoenen A, Liu W, Kochs G, Khromykh AA, Mackenzie JM (2007) West Nile virusinduced cytoplasmic membrane structures provide partial protection against the interferon-induced antiviral MxA protein. J Gen Virol 88: 3013-3017.

[87] Ambrose RL, Mackenzie JM (2011) West Nile virus differentially modulates the unfolded protein response to facilitate replication and immune evasion. J Virol 85: 27232732.

[88] Munoz-Jordan JL, Laurent-Rolle M, Ashour J, Martinez-Sobrido L, Ashok M, Lipkin WI, Garcia-Sastre A (2005) Inhibition of alpha/beta interferon signaling by the NS4B protein of flaviviruses. J Virol 79: 8004-8013.

[89] Munoz-Jordan JL, Sanchez-Burgos GG, Laurent-Rolle M, Garcia-Sastre A (2003) Inhibition of interferon signaling by dengue virus. Proc Natl Acad Sci U S A 100: 1433314338.

[90] Mackenzie JM, Khromykh AA, Parton RG (2007) Cholesterol manipulation by West Nile virus perturbs the cellular immune response. Cell Host Microbe 2: 229-239.

[91] Blanc M, Hsieh WY, Robertson KA, Watterson S, Shui G, Lacaze P, Khondoker M, Dickinson P, Sing G, Rodriguez-Martin S, Phelan P, Forster T, Strobl B, Muller M, Riemersma R, Osborne T, Wenk MR, Angulo A, Ghazal P (2011) Host defense against viral infection involves interferon mediated down-regulation of sterol biosynthesis. PLoS Biol 9: e1000598.

[92] Saka HA, Valdivia RH (2012) Emerging Roles for Lipid Droplets in Immunity and HostPathogen Interactions. Annu Rev Cell Dev Biol.

[93] Hsu NY, Ilnytska O, Belov G, Santiana M, Chen YH, Takvorian PM, Pau C, van der Schaar H, Kaushik-Basu N, Balla T, Cameron CE, Ehrenfeld E, van Kuppeveld FJ, Altan-Bonnet N (2010) Viral reorganization of the secretory pathway generates distinct organelles for RNA replication. Cell 141: 799-811.

[94] den Boon JA, Ahlquist P (2010) Organelle-like membrane compartmentalization of positive-strand RNA virus replication factories. Annu Rev Microbiol 64: 241-256.

[95] Kopek BG, Perkins G, Miller DJ, Ellisman MH, Ahlquist P (2007) Three-dimensional analysis of a viral RNA replication complex reveals a virus-induced mini-organelle. PLoS Biol 5: e220. 
[96] Jiang Y, Serviene E, Gal J, Panavas T, Nagy PD (2006) Identification of essential host factors affecting tombusvirus RNA replication based on the yeast Tet promoters Hughes Collection. J Virol 80: 7394-7404.

[97] Serviene E, Jiang Y, Cheng CP, Baker J, Nagy PD (2006) Screening of the yeast yTHC collection identifies essential host factors affecting tombusvirus RNA recombination. J Virol 80: 1231-1241.

[98] Panavas T, Serviene E, Brasher J, Nagy PD (2005) Yeast genome-wide screen reveals dissimilar sets of host genes affecting replication of RNA viruses. Proc Natl Acad Sci U S A 102: 7326-7331.

[99] Serviene E, Shapka N, Cheng CP, Panavas T, Phuangrat B, Baker J, Nagy PD (2005) Genome-wide screen identifies host genes affecting viral RNA recombination. Proc Natl Acad Sci U S A 102: 10545-10550.

[100] Lee WM, Ahlquist P (2003) Membrane synthesis, specific lipid requirements, and localized lipid composition changes associated with a positive-strand RNA virus RNA replication protein. J Virol 77: 12819-12828.

[101] Lee WM, Ishikawa M, Ahlquist P (2001) Mutation of host delta9 fatty acid desaturase inhibits brome mosaic virus RNA replication between template recognition and RNA synthesis. J Virol 75: 2097-2106.

[102] Heaton NS, Perera R, Berger KL, Khadka S, Lacount DJ, Kuhn RJ, Randall G (2010) Dengue virus nonstructural protein 3 redistributes fatty acid synthase to sites of viral replication and increases cellular fatty acid synthesis. Proc Natl Acad Sci U S A 107: 17345-17350.

[103] Cherry S, Kunte A, Wang H, Coyne C, Rawson RB, Perrimon N (2006) COPI activity coupled with fatty acid biosynthesis is required for viral replication. PLoS Pathog 2: e102.

[104] Sharma M, Sasvari Z, Nagy PD (2010) Inhibition of sterol biosynthesis reduces tombusvirus replication in yeast and plants. J Virol 84: 2270-2281.

[105] Sharma M, Sasvari Z, Nagy PD (2011) Inhibition of phospholipid biosynthesis decreases the activity of the tombusvirus replicase and alters the subcellular localization of replication proteins. Virology 415: 141-152.

[106] Vaillancourt FH, Pilote L, Cartier M, Lippens J, Liuzzi M, Bethell RC, Cordingley MG, Kukolj G (2009) Identification of a lipid kinase as a host factor involved in hepatitis C virus RNA replication. Virology 387: 5-10.

[107] Berger KL, Cooper JD, Heaton NS, Yoon R, Oakland TE, Jordan TX, Mateu G, Grakoui A, Randall G (2009) Roles for endocytic trafficking and phosphatidylinositol 4-kinase III alpha in hepatitis C virus replication. Proc Natl Acad Sci U S A 106: 7577-7582.

[108] Sasaki J, Ishikawa K, Arita M, Taniguchi K (2011) ACBD3-mediated recruitment of PI4KB to picornavirus RNA replication sites. Embo J 31: 754-766.

[109] Arita M, Kojima H, Nagano T, Okabe T, Wakita T, Shimizu H (2011) Phosphatidylinositol-4 kinase III beta is a target of enviroxime-like compounds for antipoliovirus activity. J Virol 85: 2364-2372. 
[110] Rothwell C, Lebreton A, Young Ng C, Lim JY, Liu W, Vasudevan S, Labow M, Gu F, Gaither LA (2009) Cholesterol biosynthesis modulation regulates dengue viral replication. Virology 389: 8-19.

[111] Sagan SM, Rouleau Y, Leggiadro C, Supekova L, Schultz PG, Su AI, Pezacki JP (2006) The influence of cholesterol and lipid metabolism on host cell structure and hepatitis $\mathrm{C}$ virus replication. Biochem Cell Biol 84: 67-79.

[112] Kapadia SB, Chisari FV (2005) Hepatitis C virus RNA replication is regulated by host geranylgeranylation and fatty acids. Proc Natl Acad Sci U S A 102: 2561-2566.

[113] Takano T, Tsukiyama-Kohara K, Hayashi M, Hirata Y, Satoh M, Tokunaga Y, Tateno C, Hayashi Y, Hishima T, Funata N, Sudoh M, Kohara M (2011) Augmentation of DHCR24 expression by hepatitis $C$ virus infection facilitates viral replication in hepatocytes. J Hepatol 55: 512-521.

[114] Chang KO (2009) Role of cholesterol pathways in norovirus replication. J Virol 83: 8587-8595.

[115] Quetglas JI, Hernaez B, Galindo I, Munoz-Moreno R, Cuesta-Geijo MA, Alonso C Small rho GTPases and cholesterol biosynthetic pathway intermediates in African swine fever virus infection. J Virol 86: 1758-1767.

[116] Wu SX, Ahlquist P, Kaesberg P (1992) Active complete in vitro replication of nodavirus RNA requires glycerophospholipid. Proc Natl Acad Sci U S A 89: 1113611140.

[117] Rassmann A, Henke A, Jarasch N, Lottspeich F, Saluz HP, Munder T (2007) The human fatty acid synthase: a new therapeutic target for coxsackievirus B3-induced diseases? Antiviral Res 76: 150-158.

[118] Guinea R, Carrasco L (1991) Effects of fatty acids on lipid synthesis and viral RNA replication in poliovirus-infected cells. Virology 185: 473-476.

[119] Yang W, Hood BL, Chadwick SL, Liu S, Watkins SC, Luo G, Conrads TP, Wang T (2008) Fatty acid synthase is up-regulated during hepatitis $C$ virus infection and regulates hepatitis C virus entry and production. Hepatology 48: 1396-1403.

[120] Stapleford KA, Rapaport D, Miller DJ (2009) Mitochondrion-enriched anionic phospholipids facilitate flock house virus RNA polymerase membrane association. J Virol 83: 4498-4507.

[121] Guinea R, Carrasco L (1990) Phospholipid biosynthesis and poliovirus genome replication, two coupled phenomena. Embo J 9: 2011-2016.

[122] Greninger AL, Knudsen GM, Betegon M, Burlingame AL, Derisi JL (2012) The 3A protein from multiple picornaviruses utilizes the golgi adaptor protein ACBD3 to recruit PI4KIIIbeta. J Virol 86: 3605-3616.

[123] Tai AW, Benita Y, Peng LF, Kim SS, Sakamoto N, Xavier RJ, Chung RT (2009) A functional genomic screen identifies cellular cofactors of hepatitis $C$ virus replication. Cell Host Microbe 5: 298-307.

[124] Tai AW, Salloum S (2011) The role of the phosphatidylinositol 4-kinase PI4KA in hepatitis C virus-induced host membrane rearrangement. PLoS One 6: e26300. 
[125] Reiss S, Rebhan I, Backes P, Romero-Brey I, Erfle H, Matula P, Kaderali L, Poenisch M, Blankenburg H, Hiet MS, Longerich T, Diehl S, Ramirez F, Balla T, Rohr K, Kaul A, Buhler S, Pepperkok R, Lengauer T, Albrecht M, Eils R, Schirmacher P, Lohmann V, Bartenschlager R (2011) Recruitment and Activation of a Lipid Kinase by Hepatitis C Virus NS5A Is Essential for Integrity of the Membranous Replication Compartment. Cell Host Microbe 9: 32-45.

[126] Borawski J, Troke P, Puyang X, Gibaja V, Zhao S, Mickanin C, Leighton-Davies J, Wilson CJ, Myer V, Cornellataracido I, Baryza J, Tallarico J, Joberty G, Bantscheff M, Schirle M, Bouwmeester T, Mathy JE, Lin K, Compton T, Labow M, Wiedmann B, Gaither LA (2009) Class III phosphatidylinositol 4-kinase alpha and beta are novel host factor regulators of hepatitis C virus replication. J Virol 83: 10058-10074.

[127] Lim YS, Hwang SB (2011) Hepatitis C virus NS5A protein interacts with phosphatidylinositol 4-kinase type IIIalpha and regulates viral propagation. J Biol Chem 286: 11290-11298.

[128] Levental I, Grzybek M, Simons K (2010) Greasing their way: lipid modifications determine protein association with membrane rafts. Biochemistry 49: 6305-6316.

[129] Yu GY, Lee KJ, Gao L, Lai MM (2006) Palmitoylation and polymerization of hepatitis C virus NS4B protein. J Virol 80: 6013-6023.

[130] Weng L, Hirata Y, Arai M, Kohara M, Wakita T, Watashi K, Shimotohno K, He Y, Zhong J, Toyoda $\mathrm{T}$ (2010) Sphingomyelin activates hepatitis $\mathrm{C}$ virus RNA polymerase in a genotype-specific manner. J Virol 84: 11761-11770.

[131] Ahola T, Lampio A, Auvinen P, Kaariainen L (1999) Semliki Forest virus mRNA capping enzyme requires association with anionic membrane phospholipids for activity. Embo J 18: 3164-3172.

[132] Saito K, Nishijima M, Kuge O (2006) Phosphatidylserine is involved in gene expression from Sindbis virus subgenomic promoter. Biochem Biophys Res Commun 345: 878-885.

[133] Graham TR, Kozlov MM (2010) Interplay of proteins and lipids in generating membrane curvature. Curr Opin Cell Biol 22: 430-436.

[134] Szule JA, Fuller NL, Rand RP (2002) The effects of acyl chain length and saturation of diacylglycerols and phosphatidylcholines on membrane monolayer curvature. Biophys J 83: 977-984.

[135] Fuller N, Rand RP (2001) The influence of lysolipids on the spontaneous curvature and bending elasticity of phospholipid membranes. Biophys J 81: 243-254.

[136] Ono A (2010) Relationships between plasma membrane microdomains and HIV-1 assembly. Biol Cell 102: 335-350.

[137] Waheed AA, Freed EO (2010) The Role of Lipids in Retrovirus Replication. Viruses 2: 1146-1180.

[138] Nayak DP, Balogun RA, Yamada H, Zhou ZH, Barman S (2009) Influenza virus morphogenesis and budding. Virus Res 143: 147-161. 
[139] Kalvodova L, Sampaio JL, Cordo S, Ejsing CS, Shevchenko A, Simons K (2009) The lipidomes of vesicular stomatitis virus, semliki forest virus, and the host plasma membrane analyzed by quantitative shotgun mass spectrometry. J Virol 83: 7996-8003.

[140] Mettenleiter TC, Klupp BG, Granzow H (2009) Herpesvirus assembly: an update. Virus Res 143: 222-234.

[141] Condit RC, Moussatche N, Traktman P (2006) In a nutshell: structure and assembly of the vaccinia virion. Adv Virus Res 66: 31-124.

[142] Sodeik B, Krijnse-Locker J (2002) Assembly of vaccinia virus revisited: de novo membrane synthesis or acquisition from the host? Trends Microbiol 10: 15-24.

[143] Chazal N, Gerlier D (2003) Virus entry, assembly, budding, and membrane rafts. Microbiol Mol Biol Rev 67: 226-237, table of contents.

[144] Ghanam RH, Samal AB, Fernandez TF, Saad JS (2012) Role of the HIV-1 Matrix Protein in Gag Intracellular Trafficking and Targeting to the Plasma Membrane for Virus Assembly. Front Microbiol 3: 55.

[145] Vazquez-Calvo A, Saiz JC, Sobrino F, Martin-Acebes MA (2011) Inhibition of enveloped virus infection of cultured cells by valproic Acid. J Virol 85: 1267-1274.

[146] Roingeard P, Hourioux C, Blanchard E, Prensier G (2008) Hepatitis C virus budding at lipid droplet-associated ER membrane visualized by 3D electron microscopy. Histochem Cell Biol 130: 561-566.

[147] Bartenschlager R, Penin F, Lohmann V, Andre P (2011) Assembly of infectious hepatitis $C$ virus particles. Trends Microbiol 19: 95-103.

[148] Shimizu Y, Hishiki T, Ujino S, Sugiyama K, Funami K, Shimotohno K (2011) Lipoprotein component associated with hepatitis $\mathrm{C}$ virus is essential for virus infectivity. Curr Opin Virol 1: 19-26.

[149] Majeau N, Fromentin R, Savard C, Duval M, Tremblay MJ, Leclerc D (2009) Palmitoylation of hepatitis $\mathrm{C}$ virus core protein is important for virion production. J Biol Chem 284: 33915-33925.

[150] Lindwasser OW, Resh MD (2002) Myristoylation as a target for inhibiting HIV assembly: unsaturated fatty acids block viral budding. Proc Natl Acad Sci U S A 99: 13037-13042.

[151] Moscufo N, Simons J, Chow M (1991) Myristoylation is important at multiple stages in poliovirus assembly. J Virol 65: 2372-2380.

[152] Goodwin S, Tuthill TJ, Arias A, Killington RA, Rowlands DJ (2009) Foot-and-mouth disease virus assembly: processing of recombinant capsid precursor by exogenous protease induces self-assembly of pentamers in vitro in a myristoylation-dependent manner. J Virol 83: 11275-11282.

[153] Aloia RC, Jensen FC, Curtain CC, Mobley PW, Gordon LM (1988) Lipid composition and fluidity of the human immunodeficiency virus. Proc Natl Acad Sci U S A 85: 900904.

[154] Hirschberg CB, Robbins PW (1974) The glycolipids and phospholipids of Sindbis virus and their relation to the lipids of the host cell plasma membrane. Virology 61: 602-608. 
[155] Klenk HD, Choppin PW (1971) Glycolipid content of vesicular stomatitis virus grown in baby hamster kidney cells. J Virol 7: 416-417.

[156] Brugger B, Glass B, Haberkant P, Leibrecht I, Wieland FT, Krausslich HG (2006) The HIV lipidome: a raft with an unusual composition. Proc Natl Acad Sci U S A 103: 26412646.

[157] Chan R, Uchil PD, Jin J, Shui G, Ott DE, Mothes W, Wenk MR (2008) Retroviruses human immunodeficiency virus and murine leukemia virus are enriched in phosphoinositides. J Virol 82: 11228-11238.

[158] Gerl MJ, Sampaio JL, Urban S, Kalvodova L, Verbavatz JM, Binnington B, Lindemann D, Lingwood CA, Shevchenko A, Schroeder C, Simons K (2012) Quantitative analysis of the lipidomes of the influenza virus envelope and MDCK cell apical membrane. J Cell Biol 196: 213-221.

[159] Liu ST, Sharon-Friling R, Ivanova P, Milne SB, Myers DS, Rabinowitz JD, Brown HA, Shenk T (2011) Synaptic vesicle-like lipidome of human cytomegalovirus virions reveals a role for SNARE machinery in virion egress. Proc Natl Acad Sci U S A 108: 1286912874.

[160] Merz A, Long G, Hiet MS, Brugger B, Chlanda P, Andre P, Wieland F, Krijnse-Locker J, Bartenschlager R (2011) Biochemical and morphological properties of hepatitis C virus particles and determination of their lipidome. J Biol Chem 286: 3018-3032.

[161] Moody MA, Liao HX, Alam SM, Scearce RM, Plonk MK, Kozink DM, Drinker MS, Zhang R, Xia SM, Sutherland LL, Tomaras GD, Giles IP, Kappes JC, OchsenbauerJambor C, Edmonds TG, Soares M, Barbero G, Forthal DN, Landucci G, Chang C, King SW, Kavlie A, Denny TN, Hwang KK, Chen PP, Thorpe PE, Montefiori DC, Haynes BF (2010) Anti-phospholipid human monoclonal antibodies inhibit CCR5-tropic HIV-1 and induce beta-chemokines. J Exp Med 207: 763-776.

[162] Teissier E, Zandomeneghi G, Loquet A, Lavillette D, Lavergne JP, Montserret R, Cosset FL, Bockmann A, Meier BH, Penin F, Pecheur EI (2011) Mechanism of inhibition of enveloped virus membrane fusion by the antiviral drug arbidol. PLoS One 6: e15874.

[163] Boriskin YS, Leneva IA, Pecheur EI, Polyak SJ (2008) Arbidol: a broad-spectrum antiviral compound that blocks viral fusion. Curr Med Chem 15: 997-1005.

[164] Wolf MC, Freiberg AN, Zhang T, Akyol-Ataman Z, Grock A, Hong PW, Li J, Watson NF, Fang AQ, Aguilar HC, Porotto M, Honko AN, Damoiseaux R, Miller JP, Woodson SE, Chantasirivisal S, Fontanes V, Negrete OA, Krogstad P, Dasgupta A, Moscona A, Hensley LE, Whelan SP, Faull KF, Holbrook MR, Jung ME, Lee B (2010) A broadspectrum antiviral targeting entry of enveloped viruses. Proc Natl Acad Sci U S A 107: 3157-3162.

[165] Berkhout B, Eggink D, Sanders RW (2012) Is there a future for antiviral fusion inhibitors? Curr Opin Virol 2: 50-59.

[166] Andrei G, De Clercq E, Snoeck R (2008) Novel inhibitors of human CMV. Curr Opin Investig Drugs 9: 132-145. 
[167] Graci JD, Cameron CE (2006) Mechanisms of action of ribavirin against distinct viruses. Rev Med Virol 16: 37-48.

[168] De Clercq E (2009) The history of antiretrovirals: key discoveries over the past 25 years. Rev Med Virol 19: 287-299.

[169] Olschlager S, Neyts J, Gunther S (2011) Depletion of GTP pool is not the predominant mechanism by which ribavirin exerts its antiviral effect on Lassa virus. Antiviral Res 91: 89-93.

[170] Liu Z, Guo Z, Wang G, Zhang D, He H, Li G, Liu Y, Higgins D, Walsh A, ShanahanPrendergast L, Lu J (2009) Evaluation of the efficacy and safety of a statin/caffeine combination against H5N1, H3N2 and H1N1 virus infection in BALB/c mice. Eur J Pharm Sci 38: 215-223.

[171] Brett SJ, Myles P, Lim WS, Enstone JE, Bannister B, Semple MG, Read RC, Taylor BL, McMenamin J, Nicholson KG, Nguyen-Van-Tam JS, Openshaw PJ (2011) Pre-admission statin use and in-hospital severity of 2009 pandemic influenza A(H1N1) disease. PLoS One 6: e18120.

[172] Mihaila R, Nedelcu L, Fratila O, Rezi EC, Domnariu C, Ciuca R, Zaharie AV, Olteanu A, Bera L, Deac M (2009) Lovastatin and fluvastatin reduce viremia and the proinflammatory cytokines in the patients with chronic hepatitis C. Hepatogastroenterology 56: 1704-1709.

[173] Bader T, Fazili J, Madhoun M, Aston C, Hughes D, Rizvi S, Seres K, Hasan M (2008) Fluvastatin inhibits hepatitis C replication in humans. Am J Gastroenterol 103: 13831389.

[174] Gilbert C, Bergeron M, Methot S, Giguere JF, Tremblay MJ (2005) Statins could be used to control replication of some viruses, including HIV-1. Viral Immunol 18: 474-489.

[175] Giguere JF, Tremblay MJ (2004) Statin compounds reduce human immunodeficiency virus type 1 replication by preventing the interaction between virion-associated host intercellular adhesion molecule 1 and its natural cell surface ligand LFA-1. J Virol 78: 12062-12065.

[176] Montoya CJ, Jaimes F, Higuita EA, Convers-Paez S, Estrada S, Gutierrez F, Amariles P, Giraldo N, Penaloza C, Rugeles MT (2009) Antiretroviral effect of lovastatin on HIV-1infected individuals without highly active antiretroviral therapy (The LIVE study): a phase-II randomized clinical trial. Trials 10: 41.

[177] Poh MK, Shui G, Xie X, Shi PY, Wenk MR, Gu F (2012) U18666A, an intra-cellular cholesterol transport inhibitor, inhibits dengue virus entry and replication. Antiviral Res 93: 191-198.

[178] Huang H, Chen Y, Ye J (2007) Inhibition of hepatitis C virus replication by peroxidation of arachidonate and restoration by vitamin E. Proc Natl Acad Sci U S A 104: 18666-18670.

[179] Bianco A, Reghellin V, Donnici L, Fenu S, Alvarez R, Baruffa C, Peri F, Pagani M, Abrignani S, Neddermann P, De Francesco R (2012) Metabolism of phosphatidylinositol 
4-kinase IIIalpha-dependent PI4P Is subverted by HCV and is targeted by a 4-anilino quinazoline with antiviral activity. PLoS Pathog 8: e1002576.

[180] Tatematsu K, Tanaka Y, Sugiyama M, Sudoh M, Mizokami M (2011) Host sphingolipid biosynthesis is a promising therapeutic target for the inhibition of hepatitis B virus replication. J Med Virol 83: 587-593.

[181] Umehara T, Sudoh M, Yasui F, Matsuda C, Hayashi Y, Chayama K, Kohara M (2006) Serine palmitoyltransferase inhibitor suppresses HCV replication in a mouse model. Biochem Biophys Res Commun 346: 67-73.

[182] Amemiya F, Maekawa S, Itakura Y, Kanayama A, Matsui A, Takano S, Yamaguchi T, Itakura J, Kitamura T, Inoue T, Sakamoto M, Yamauchi K, Okada S, Yamashita A, Sakamoto N, Itoh M, Enomoto N (2008) Targeting lipid metabolism in the treatment of hepatitis C virus infection. J Infect Dis 197: 361-370.

[183] Gower TL, Graham BS (2001) Antiviral activity of lovastatin against respiratory syncytial virus in vivo and in vitro. Antimicrob Agents Chemother 45: 1231-1237.

[184] Weitz-Schmidt G, Welzenbach K, Brinkmann V, Kamata T, Kallen J, Bruns C, Cottens S, Takada Y, Hommel U (2001) Statins selectively inhibit leukocyte function antigen-1 by binding to a novel regulatory integrin site. Nat Med 7: 687-692.

[185] Weitz-Schmidt G (2003) Lymphocyte function-associated antigen-1 blockade by statins: molecular basis and biological relevance. Endothelium 10: 43-47.

[186] Weitz-Schmidt G (2002) Statins as anti-inflammatory agents. Trends Pharmacol Sci 23: 482-486.

[187] Harrison SA, Rossaro L, Hu KQ, Patel K, Tillmann H, Dhaliwal S, Torres DM, Koury K, Goteti VS, Noviello S, Brass CA, Albrecht JK, McHutchison JG, Sulkowski MS (2010) Serum cholesterol and statin use predict virological response to peginterferon and ribavirin therapy. Hepatology 52: 864-874.

[188] Mihaila RG, Nedelcu L, Fratila O, Retzler L, Domnariu C, Cipaian RC, Rezi EC, Beca C, Deac M (2011) Effects of simvastatin in patients with viral chronic hepatitis C. Hepatogastroenterology 58: 1296-1300.

[189] Patel K, Lim SG, Cheng CW, Lawitz E, Tillmann HL, Chopra N, Altmeyer R, Randle JC, McHutchison JG (2011) Open-label phase $1 \mathrm{~b}$ pilot study to assess the antiviral efficacy of simvastatin combined with sertraline in chronic hepatitis $\mathrm{C}$ patients. Antivir Ther 16: 1341-1346.

[190] Kwong JC, Li P, Redelmeier DA (2009) Influenza morbidity and mortality in elderly patients receiving statins: a cohort study. PLoS One 4: e8087.

[191] Cenedella RJ (2009) Cholesterol synthesis inhibitor U18666A and the role of sterol metabolism and trafficking in numerous pathophysiological processes. Lipids 44: 477487.

[192] Halvorson DL, McCune SA (1984) Inhibition of fatty acid synthesis in isolated adipocytes by 5-(tetradecyloxy)-2-furoic acid. Lipids 19: 851-856. 
[193] Seronello S, Ito C, Wakita T, Choi J (2010) Ethanol enhances hepatitis C virus replication through lipid metabolism and elevated NADH/NAD+. J Biol Chem 285: 845854.

[194] Loftus TM, Jaworsky DE, Frehywot GL, Townsend CA, Ronnett GV, Lane MD, Kuhajda FP (2000) Reduced food intake and body weight in mice treated with fatty acid synthase inhibitors. Science 288: 2379-2381.

[195] Kuhajda FP, Landree LE, Ronnett GV (2005) The connections between C75 and obesity drug-target pathways. Trends Pharmacol Sci 26: 541-544.

[196] Wang C, Gale M, Jr., Keller BC, Huang H, Brown MS, Goldstein JL, Ye J (2005) Identification of FBL2 as a geranylgeranylated cellular protein required for hepatitis $\mathrm{C}$ virus RNA replication. Mol Cell 18: 425-434.

[197] Shaltiel G, Shamir A, Shapiro J, Ding D, Dalton E, Bialer M, Harwood AJ, Belmaker RH, Greenberg ML, Agam G (2004) Valproate decreases inositol biosynthesis. Biol Psychiatry 56: 868-874.

[198] Tokuoka SM, Saiardi A, Nurrish SJ (2008) The mood stabilizer valproate inhibits both inositol- and diacylglycerol-signaling pathways in Caenorhabditis elegans. Mol Biol Cell 19: 2241-2250.

[199] Xu X, Muller-Taubenberger A, Adley KE, Pawolleck N, Lee VW, Wiedemann C, Sihra TS, Maniak M, Jin T, Williams RS (2007) Attenuation of phospholipid signaling provides a novel mechanism for the action of valproic acid. Eukaryot Cell 6: 899-906.

[200] Soares MM, King SW, Thorpe PE (2008) Targeting inside-out phosphatidylserine as a therapeutic strategy for viral diseases. Nat Med 14: 1357-1362.

[201] Gerber DE, Stopeck AT, Wong L, Rosen LS, Thorpe PE, Shan JS, Ibrahim NK (2011) Phase I safety and pharmacokinetic study of bavituximab, a chimeric phosphatidylserine-targeting monoclonal antibody, in patients with advanced solid tumors. Clin Cancer Res 17: 6888-6896.

[202] Knight ZA, Gonzalez B, Feldman ME, Zunder ER, Goldenberg DD, Williams O, Loewith R, Stokoe D, Balla A, Toth B, Balla T, Weiss WA, Williams RL, Shokat KM (2006) A pharmacological map of the PI3-K family defines a role for p110alpha in insulin signaling. Cell 125: 733-747.

[203] Arita M, Wakita T, Shimizu H (2009) Cellular kinase inhibitors that suppress enterovirus replication have a conserved target in viral protein $3 \mathrm{~A}$ similar to that of enviroxime. J Gen Virol 90: 1869-1879.

[204] De Palma AM, Thibaut HJ, van der Linden L, Lanke K, Heggermont W, Ireland S, Andrews R, Arimilli M, Al-Tel TH, De Clercq E, van Kuppeveld F, Neyts J (2009) Mutations in the nonstructural protein $3 \mathrm{~A}$ confer resistance to the novel enterovirus replication inhibitor TTP-8307. Antimicrob Agents Chemother 53: 1850-1857.

[205] Heinz BA, Vance LM (1995) The antiviral compound enviroxime targets the 3A coding region of rhinovirus and poliovirus. J Virol 69: 4189-4197. 
[206] Miller ME, Adhikary S, Kolokoltsov AA, Davey RA (2012) Ebolavirus requires acid sphingomyelinase activity and plasma membrane sphingomyelin for infection. J Virol. 86:7473-7483.

[207] Ciesek S, Steinmann E, Manns MP, Wedemeyer H, Pietschmann T (2008) The suppressive effect that myriocin has on hepatitis $C$ virus RNA replication is independent of inhibition of serine palmitoyl transferase. J Infect Dis 198: 1091-1093.

[208] Doucleff M (2010) Select: Lipids out loud. Cell 143: 853-855. 